\title{
Information, Knowledge, and Attitudes: An Evaluation of the Taxpayer Receipt
}

\author{
Lucy Barnes, University College London \\ Avi Feller, University of California, Berkeley \\ Jake Haselswerdt, University of Missouri \\ Ethan Porter, George Washington University
}

To better understand the relationship between information and political knowledge, we evaluate an ambitious government initiative: the nationwide dissemination of "taxpayer receipts," or personalized, itemized accounts of government spending, by the UK government in fall 2014. In coordination with the British tax authorities, we embedded a survey experiment in a nationally representative panel. We find that citizens became more knowledgeable about government spending because of our encouragement to read their receipt. Although baseline levels of political knowledge are indeed low, our findings indicate that individuals are capable of learning and retaining complex political information. However, even as citizens became more knowledgeable, we uncover no evidence that their attitudes toward government and redistribution changed concomitantly. The acquisition and retention of new information does not necessarily change attitudes. Our results have implications for citizens' capacity to learn and research on the relationship between knowledge and attitudes.

n 2014, the United Kingdom mailed 26 million taxpayers

"taxpayer receipts" for the first time. The receipts itemized government spending over the previous year, personalized for each recipient. What changed when citizens were exposed to this information? Were there effects on political knowledge and attitudes? More broadly, can people increase their political knowledge about complex policy matters, and does increased knowledge coincide with attitude change? To shed light on such questions, we administered a field experiment in coordination with the UK tax authorities during the distribution of the receipts. We found that, while the receipts increased political knowledge, they had no effect on related attitudes.

Our findings contribute to an ongoing debate about political knowledge. On the one hand, there is ample reason to doubt that citizens are capable of learning about complex policy matters. Political scientists have long been skeptical about the public's capacity to absorb and retain complicated information (Delli Carpini and Keeter 1996). Others have argued that such skepticism is overstated and that, indeed, citizens can learn (Gerber and Green 1999). We examine an actual policy intervention to show that citizens are capable of learning outside the laboratory. Our effect sizes come close to approximating those observed in the lab studies of Prior and Lupia (2008). We also show that the increase holds over the medium run. However, the increase in knowledge does not appear to coincide with attitude change. Citizens can learn, but we find no evidence that they change their minds as a result.

\section{INFORMATIONAL EFFECTS ON KNOWLEDGE, ATTITUDES, PREFERENCES}

The potential effects of information on political knowledge, attitudes, and preferences are distinct. Conceptually, knowl-

Lucy Barnes (l.barnes@ucl.ac.uk) is a lecturer in comparative politics at University College London, WC1H 9QU, UK. Avi Feller (afeller@berkeley.edu) is an assistant professor at the University of California, Berkeley. Jake Haselswerdt (haselswerdtj@missouri.edu) is an assistant professor at the University of Missouri, Columbia, Missouri 65211. Ethan Porter (evporter@gwu.edu) is an assistant professor at George Washington University.

This study was deemed exempt from formal ethical review by the University of Chicago Institutional Review Board (IRB14-0237). Financial support for this research was provided by the Omidyar Network. Data and supporting materials necessary to reproduce the numerical results in the article are available in the JOP Dataverse (https://dataverse.harvard.edu/dataverse/jop). An online appendix with supplementary material is available at http://dx.doi.org/10 $.1086 / 695672$.

The Journal of Politics, volume 80, number 2. Published online February 23, 2018. http://dx.doi.org/10.1086/695672

(C) 2018 by the Southern Political Science Association. All rights reserved. 0022-3816/2018/8002-0024\$10.00 
edge requires the assimilation of information, attitudes require combining assimilation with an evaluation, and policy preferences require the application of both of these to a choice over a government action. This distinction reflects recent experimental findings, which indicate that while knowledge and attitudes may be elastic to the provision of information, preferences over policy are much more difficult to move (Grigorieff, Roth, and Ubfal 2016; Kuziemko et al. 2015).

It is tempting to view the relationship between knowledge and information as straightforward, with the latter acting as a necessary condition of the former. Yet scholarship on motivated reasoning makes clear that the relationship is not always straightforward. Subjects will often seek out new information to reach conclusions that accord with their prior preferences (Lodge and Taber 2013). In lab studies, only the most aggressive techniques - described as "hitting subjects between the eyes"-have occasioned increases in knowledge (Kuklinski et al. 2000). There is even some evidence that presenting subjects with factual information will cause them to become further entrenched in their prior misperceptions (Nyhan and Reifler 2010). While the "backfire effect" may be overstated (Wood and Porter 2018), in general the literature encourages some skepticism about the capacity of citizens to learn new information. With that in mind, we examine whether taxpayer receipts can increase knowledge about the government budget.

In terms of attitudes and preferences, we focus on outcomes closely related to the information provided by the receipts. First, we consider attitudes toward trust and fairness. Then we consider preferences over taxation: views on taxes paid by the respondents themselves and taxes on high- and low-income households. The expectations of transparency advocates, as well as literature on the "submerged state," drive the expectation that the taxpayer receipt will make citizens evaluate government more favorably and support higher taxation (Mettler 2011).

However, the motivation for the taxpayer receipt in the UK, its introduction by Conservative politicians, and its support from advocates of low taxation and small government highlight an alternative expectation. The design of the receipts, emphasizing the size of tax payments, individual contributions to debt interest payment, and the itemization of the indirect taxes not included in the receipt speak to the primary goal of highlighting costs to individuals, rather than the benefits of government. This underpins alternative hypotheses for attitudes and preferences based on fiscal illusion: that government will be evaluated less favorably when citizens see its costs directly (Buchanan 1977).

Substantively, our work echoes Cook, Jacobs, and Kim (2010), who exploit the birthday-based distribution of So- cial Security statements in the United States to investigate the relationship between political knowledge and related attitudes. However, our results diverge from theirs, as we discuss below.

\section{HYPOTHESES}

We preregistered all hypotheses discussed here and specified their operationalization more fully, in the preregistration database Evidence in Governance and Politics (E-GAP). We have the following hypotheses:

H1. The taxpayer receipts will increase knowledge about the government budget.

H2. The receipts will change subjects' attitudes toward government,

a) increasing their trust in government, their perceptions of value for money and of fairness.

b) decreasing their trust in government, their perceptions of value for money and of fairness.

H3. The taxpayer receipts will change policy preferences,

a) increasing support for (or acquiescence toward) taxation.

b) decreasing support for (or acquiescence toward) taxation.

The expectations of "good-for-government" effects come from the literature on transparency (hypothesis 2a) and the submerged state (hypothesis $3 a$ ), whereas negative effects might be expected given the political emphasis on costs and waste underpinning the statements' introduction in the British case.

\section{EMPIRICAL STRATEGY: THE UK TAXPAYER RECEIPTS}

Before the distribution of the receipts in mid-November 2014, we fielded an initial survey wave, asking questions about knowledge, attitudes, and preferences (as described below). We also accessed demographic characteristics such as education, region, and income. At the end of the survey, a random subset of our panelists received encouragement to read the receipts that would soon be arriving in the mail. In early December, new messages were sent to all respondents: those in the treatment group were reminded that they were part of a study concerning the receipts; those in the control group simply were reminded that they were part of an ongoing study. The final survey wave was administered from the end of December to the first week in January, immediately after all the 
(4) HM Revenue \& Customs

\section{Your Annual Tax Summary 2013-14}

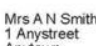

Mnystreet
Anytown
$W \times 12 Y Z$

Dear Mrs Smith

For the first time we are sending you an Annual Tax

Summary. This is to show you how your Income Tax and National Insurance contributions (NICs) are calculated and how your money is spent by the government.

This is for your information. You do not need to contact us as this is not a demand for payment.

This is how we worked out your tax for 2013-14 Your taxable income

employment

Your income before tax

Less your 2013-14 tax free amount

You pay tax on

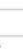

$£ 60000.00$

For more information

go to www.gov.ukl

annual-tax-summary

Go to our website to find out more about

your Tax Summary, and for a
indirect taxes such as VAT.

Your taxable income

$£ 60000.00$

$\varepsilon 6000000$ We know this trom information supplied

$£ 60000.00$

$£ 50560.00$

Your tax was calculated as

Income Tax

Higher rate Income Tax

Total Income Tax

Total Income Tax and NICs $\quad £ 18236.40$

Your income after tax and NICs

$£ 41763.60$

Your employer pays

National Insurance contributions (NICs)
Tax free amount $£ 9440.00$

After your allowances, deductions and
expenses your total tax free amount

for 2013-14 is £9440.00. This is the

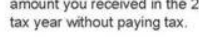

Your tax and NICs

$£ 18236.40$

87217.95 For is $30 \%$ of your faxable income. in Income Tax and NICs.

Your income after tax and NICs

$£ 41763.60$

This is your income after Income Tax
and NICs

How your tax was spent in 2013-14

The information on this page shows you how your Income Tax and National Insurance contributions were spent in 2013-14. This does not include indirect taxes such as VAT and other duties.

For more information about your tax and public spending,

go to www.gov.uk/annual-tax-summary

How your tax contributed

to public spending

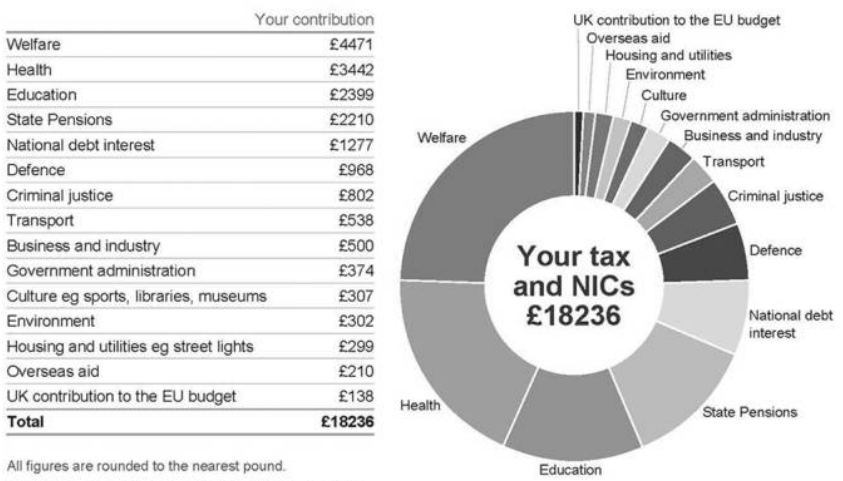

The figures in the table above are intended as a guide to
how taxes are spent and not as a direct link between your how taxes are spent and not as a direct link between your
Income Tax, National Insurance contributions and any

specific expenditure.

If you would like to opt out of receiving future tax summaries please register at
www. gov.uklannual-tax-summary

Spending information is published by HM Treasury.
The table on the other side of this page shows how the government has spent
your taxes.

Tax Summary for Mrs A N Smith for the tax year 2013-14

Figure 1. Example tax statement for a taxpayer with annual income of $£ 60,000$

receipts had been distributed. Subjects in the encouragement group were told that the survey was part of the study that they were enrolled in, while subjects in control were told that they would answer questions about "important social and political matters." We repeated the same survey questions from wave 1 and additionally asked whether respondents recalled receiving a receipt over the previous six weeks. Figure 1 shows an example of the receipt, which was sent to every pay-as-you-earn taxpayer. ${ }^{1}$

YouGov UK was responsible for implementing the survey and collecting responses. Via a nationally representative online panel, 2,529 subjects completed the survey in wave 1; 2,072 subjects did so in wave $2 .^{2}$ Subjects who were not eligible to receive a receipt were excluded from the study.

1. Pay-as-you-earn (PAYE) is the British equivalent of withholding from wage and salary income in the US federal income tax.

2. We observe modest differential attrition across treatment groups. As we show in the appendix, available online, correcting for this via inverse probability weighting (Gerber and Green 2012) leaves the results essentially unchanged.
There are two strengths of our approach. First, we examine the impact of an actual policy intervention. This mitigates questions about realism that hinder many lab- and surveybased approaches. The provenance of the information-arriving on the doormat with the official imprimatur of HMRCmay make recipients more attentive to it and give it more credibility. Second, we examine outcomes in the medium run, instead of immediately as most lab and survey experiments are forced to do. Only 4\% of our respondents who recalled receiving a receipt recalled doing so within the previous week; about one-quarter each reported a two, three, or four week interval between receipt and survey.

We maintain experimental control via an encouragement design (see, e.g., Sovey and Green 2011). Comparing the outcomes of interest in wave 2 for individuals across experimental conditions yields an intent-to-treat estimate. In this case, the intent to treat holds the primary substantive interest, as government will have difficulty forcing compliance with information dissemination. We pair the encouragement with an 
incentive - entry into a raffle on a popular survey platformto increase compliance and accuracy (Prior, Sood, and Khanna 2015). This may raise the concern that the incentive contributes more directly to our results than the treatment. As discussed in the appendix, our sensitivity analysis cautions against this interpretation, as does the weakness of the incentive. But for those who remain skeptical, the policy significance of our results remain: a small incentive to read a complex government document can improve political knowledge.

\section{OPERATIONALIZATION AND MEASUREMENT OF DEPENDENT VARIABLES}

We used three questions, all with the same structure, to measure knowledge. We asked: "Over the past twelve months, what percentage of the tax money that you paid would you say the government actually spent on $X$ ?" where $X$ is overseas aid, national defense, or health. Subjects provided numerical estimates. We use these answers to construct an index of knowledge. We code as "correct" any response that lies within 5 percentage points of the true value (i.e., the range of correct responses is 10 percentage points). For example, the share of the budget spent on defense was $5.4 \%$, meaning that any answer between 0.4 and 10.4 would be coded as correct. We think that the knowledge necessary to hold government accountable is better operationalized categorically, so we prefer the 10 percentage point window as a measure of knowledge to a continuous measure of the difference between the estimate and the true value. As we show in the appendix, our results are not sensitive to the precise cutoff we use, and we draw similar substantive conclusions looking at individual knowledge items.

Our attitude measures relate to respondents' evaluations of various government characteristics. We ask whether respondents feel that people like them are treated fairly by government and whether they can trust the government to do what is right. We ask whether they think tax money is wasted and whether the government provides good value for money. For a response somewhat closer to actual behavior, we also ask whether tax avoidance can be justified.

Finally, we measure three kinds of attitudes on taxation to capture policy preferences. First, we ask whether respondents think their own tax burden is too high. Then, we ask about progressivity: we ask respondents whether tax rates for the top income quintile should be higher than rates for the middle and lowest income quintiles (these are the "tax on rich" and "tax on poor" variables). For all variables, we recode the responses so that higher values correspond to more pro-government (higher trust, lower evaluation of waste) or more pro-redistribution (supportive of progressive rates and higher levels of tax) views. With the exception of the question about waste (which has three possible outcomes), all the atti-

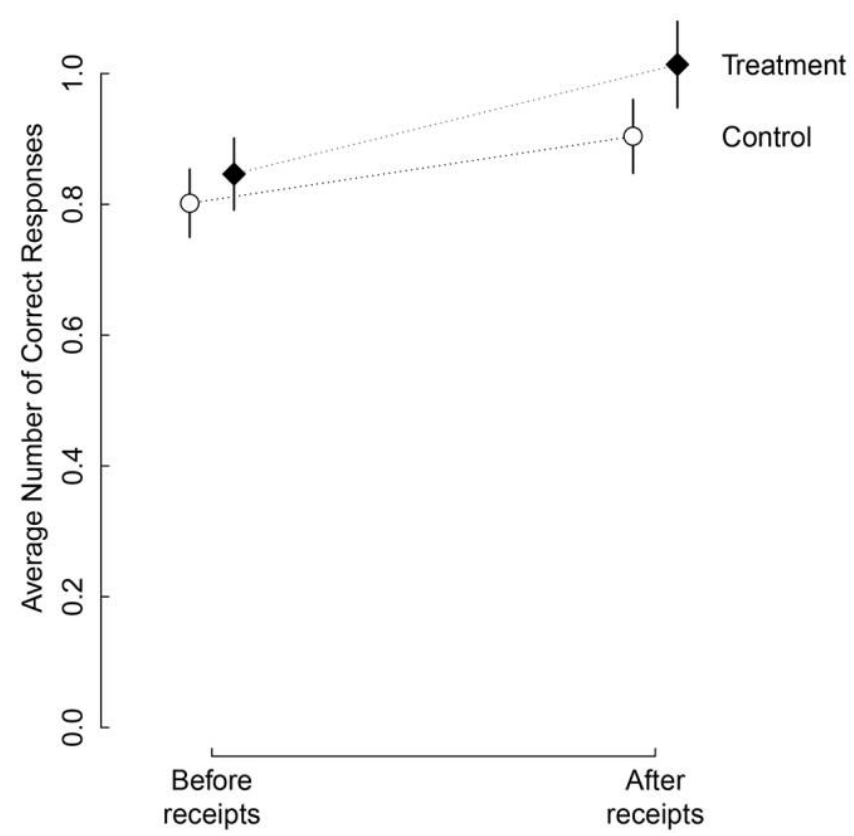

Figure 2. Comparing means: treatment and control groups before and after the distribution of the taxpayer receipts.

tude and preference questions yield responses on a five-point scale.

\section{RESULTS}

On average, respondents in the encouragement group offered 1.01 correct answers in the second wave, while those in the control group gave 0.90 correct answers, a difference of $0.11(p=.012, \mathrm{SE}=.044)$. These simple averages are displayed graphically in figure 2 . The figure also shows that the overall number of correct answers increased between the first and second waves.

Although the experimental groups are balanced on a range of demographic and political variables, there is mild imbalance in political knowledge in the first wave. We therefore estimate the impact of encouragement controlling for pretreatment covariates and wave 1 knowledge. The estimated impact of the encouragement is 0.07 correct answers $(p=.036$, $\mathrm{SE}=.035)$, comparable to the unadjusted estimate. See appendix table 4 for additional details.

We also conduct a standard manipulation check. In the encouragement group, $29 \%$ of respondents recalled receiving the taxpayer receipt, compared to $24 \%$ of the control group $(p=.025)$. This is a meaningful, if modest, increase. Finally, we use ordinal logistic regression to assess the impact of the encouragement on attitude and preference outcomes, as shown in figure $3 .^{3}$ The point estimates for all the attitude and pref-

3. Linear models of the attitude and preference outcomes yield similarly null results. 


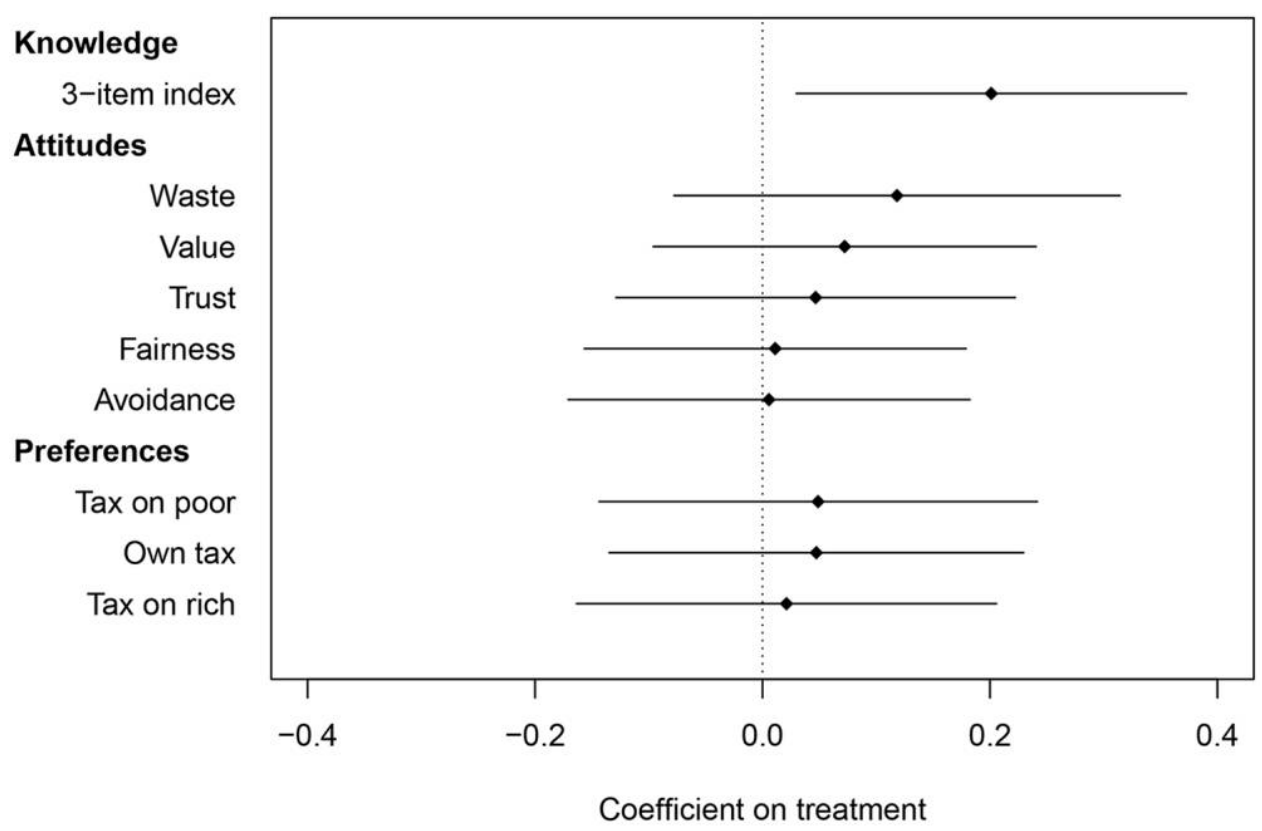

Figure 3. Taxpayer receipt encouragement effects on wave 2 knowledge, attitudes, preferences. Outcomes are ordered so that higher values indicate more "pro-government" responses or higher knowledge. Coefficient estimates and 95\% confidence intervals are from ordinal logistic models including wave 1 outcome measures and pretreatment characteristics: gender, age, region, party preference, education, employment status, income.

erence outcomes are weakly positive, but none reach conventional levels of statistical significance. ${ }^{4}$

Our findings diverge from Cook et al. (2010), whose analyses indicate that assignment to receive a Social Security statement increases confidence that benefits will be available later but has no effect on knowledge. ${ }^{5}$ But our results broadly replicate recent findings which show that citizens can increase their quantity of complex political knowledge. Our findings do not depend on highly controlled laboratory settings; instead, they are observed in the real world, thanks to an actual policy intervention. And in that same setting, we offer evidence showing that knowledge increases do not necessarily coincide with related attitude change.

\section{CONCLUSION}

Citizens can gain complex political knowledge not just in tightly controlled laboratory settings but also in the real world. Indeed, the increase we observe approximates the lower bound of the knowledge gain estimated by previous laboratory research (Prior and Lupia 2008). The widespread dissemination

4. We note that this absence of evidence of effects on attitudes and preferences is not itself evidence of absence: imprecision in the estimates means that we cannot rule out changes in attitudes or preferences smaller than 0.16 on the scale of the linear predictor, or 1.18 in odds ratio terms.

5. They also find that recalling the statement, conditional on assignment to receive it, has positive effects on both, but since recall itself is not randomly assigned, this is not directly comparable to our findings here. of fiscal facts by government can improve public knowledge of the budget, including those items that are notoriously misconstrued. At the same time, we find no evidence that this increased knowledge is accompanied by change in related attitudes, although we cannot rule out modest effects. Importantly, we reach these conclusions by assessing a real-world policy intervention.

Our findings should encourage advocates of government transparency, as well as those who argue that pessimism about citizens' capacity to learn is overstated. Simply by receiving personalized information in the mail about otherwise complex topics, people can be made more knowledgeable. When policy makers provide more information about fiscal matters to citizens, recrimination is not inevitable. Instead, citizens can learn without also changing their related attitudes. The provision of budget information should and can be an issue of good governance and the cultivation of an educated citizenry, not partisan politics.

\section{ACKNOWLEDGMENTS}

We thank Laura Bacon and the Omidyar Network for financial support. We thank E. J. Dionne, Anthony Fowler, Donald P. Green, Brendan Nyhan, Jason Reifler, and John Sides for their comments. We also thank Richard Thaler, Michael Hallsworth, and the teams at the Behavioral Insights Team and Her Majesty's Revenue and Customs for their support. All errors and omissions are our own. 


\section{REFERENCES}

Buchanan, James M. 1977. The Collected Works of James M. Buchanan, vol. 8, Democracy in Deficit: The Political Legacy of Lord Keynes. Carmel, IN: Liberty Fund.

Cook, Fay Lomax, Lawrence R. Jacobs, and Dukhong Kim. 2010. “Trusting What You Know: Information, Knowledge, and Confidence in Social Security." Journal of Politics 72 (2): 397-412.

Delli Carpini, Michael X., and Scott Keeter. 1996. What Americans Know about Politics and Why It Matters. New Haven, CT: Yale University Press.

Gerber, Alan S., and Donald P. Green. 1999. "Misperceptions about Perceptual Bias.” Annual Review of Political Science 2:189-210.

Gerber, Alan S., and Donald P. Green. 2012. Field Experiments: Design, Analysis and Interpretation. New York: Norton.

Grigorieff, Alexis, Christopher Roth, and Diego Ubfal. 2016. "Does Information Change Attitudes towards Immigrants? Representative Evidence from Survey Experiments.” IZA Discussion Paper no. 10419, Institute of Labor Economics, Bonn.

Kuklinski, James H., Paul J. Quirk, Jennifer Jerit, David Schwieder, and Robert F. Rich. 2000. "Misinformation and the Currency of Democratic Citizenship." Lournal of Politics 62 (3): 790-816.

Kuziemko, Ilyana, Michae I. Norton, Emannuel Saez, and Sfefanie Stantcheva. 2015. "How Elastic Are Preferences for Redistribution? Evi-

dence from Randomized Survey Experiments." American Economic Review 105 (4): 1478-1508.

Lodge, Milton, and Charles Taber. 2013. The Rationalizing Voter. New York: Cambridge University Press.

Mettler, Suzanne. 2011. The Submerged State: How Invisible Government Policies Undermine American Democracy. Chicago: University of Chicago Press.

Nyhan, Brendan, and Jason Reifler. 2010. "When Corrections Fail: The Persistence of Political Misperceptions.” Political Behavior 32 (2): 303-30.

Prior, Marcus, and Arthur Lupia. 2008. "Money, Time, and Political Knowledge: Distinguishing Quick Recall and Political Learning Skills.” American Journal of Political Science 52 (1): 169-83.

Prior, Marcus, Guarav Sood, and Khabir Khanna. 2015. "You Cannot Be Serious: The Impact of Accuracy Incentives on Partisan Bias in Reports of Economic Perceptions." Quarterly Journal of Political Science 10 (4): 489-518.

Sovey, Allison J., and Donald P. Green. 2011. "Instrumental Variables Estimation in Political Science: A Readers' Guide." American Journal of Political Science 55 (1): 188-200.

Wood, Thomas, and Ethan Porter. 2018. "The Elusive Backfire Effect: Mass Attitudes' Steadfast Factual Adherence." Political Behavior. doi:10 .1007/s11109-018-9443-y. 